\title{
POST-OPERATIVE FERTILITY \\ IN MARES WITH \\ CERVICAL DEFECTS
}

\author{
By \\ CHELSEA LYNN MAKLOSKI-COHORN \\ Bachelor of Science in Animal Science \\ Doctorate of Veterinary Medicine \\ Oklahoma State University \\ Stillwater, Oklahoma \\ 2009
}
Submitted to the Faculty of the
Graduate College of the
Oklahoma State University
in partial fulfillment of
the requirements for
the Degree of
MASTER OF SCIENCE

July, 2009 


\section{POST-OPERATIVE FERTILITY \\ IN MARES WITH \\ CERVICAL DEFECTS}

Thesis Approved:

\begin{tabular}{c} 
Dr. G. Reed Holyoak \\
\hline Thesis Adviser \\
Dr. Timothy Snider \\
\hline Dr. Lyndi Gilliam \\
\hline Dr. A. Gordon Emslie
\end{tabular}




\section{ACKNOWLEDGMENTS}

My foremost thanks goes to Dr. Michelle LeBlanc, an incredible mentor and brilliant theriogenologist, whom without her aid this project would not have been possible. I would like to thank her for her recommendations and insight into the nature of this study.

I am also grateful for Dr. G. Reed Holyoak. All of his support and always asking "why" has made me consider how to best approach a situation and not just take everything at face value. He has helped me grow as a veterinarian and instructor. Without his guidance I would not be where I am today.

I would also like to thank Dr. Rolf Embertson for sharing his remarkable surgical skills and showing this young veterinarian how to approach a cervical defect surgery and giving these mares another chance.

Drs. Lyndi Gilliam and Tim Snider for serving on my graduate committee and putting up with the last minute details I throw at them.

I really must thank Dr. Mark Payton for helping me muddle through all of the numbers that comprised this retrospective study to come up with publishable data. I would have been lost without his aid. 


\section{TABLE OF CONTENTS}

$\begin{array}{lll}\text { Chapter } & \text { Page }\end{array}$

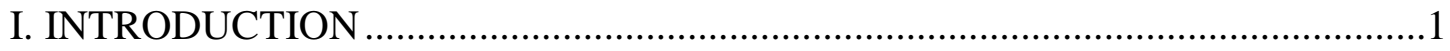

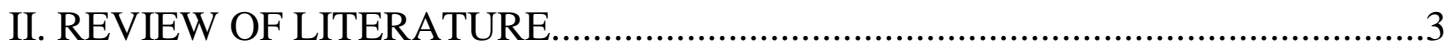

Cervical Defects and Associated Fertility..........................................................

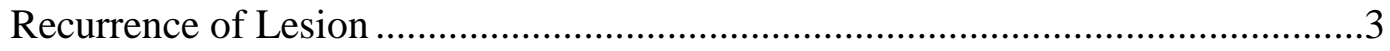

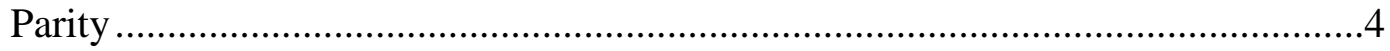

Chronicity of Barren State Prior to Surgery ……………......................................5

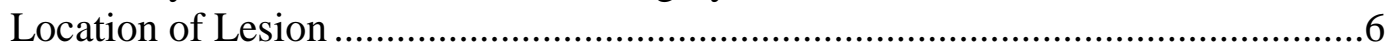

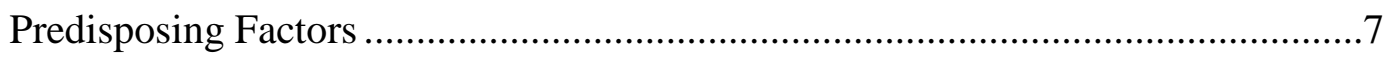

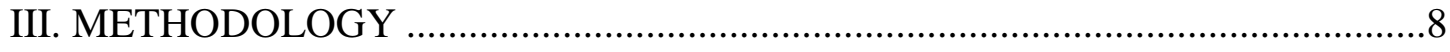

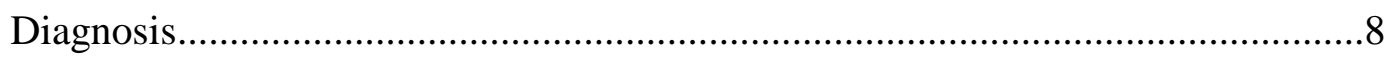

Surgical Technique - Cervical Laceration..........................................................10

Surgical Technique - Cervical Adhesion ..........................................................11

Peri- and Post-Operative Support …………..............................................11

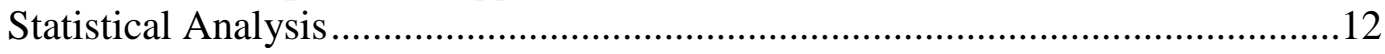

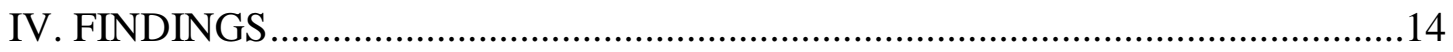

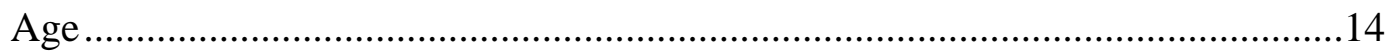

Population and Procedures.........................................................................14

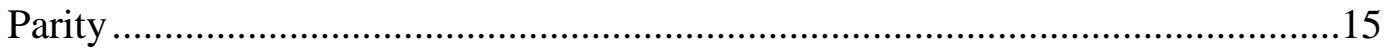

Lesion Location ..............................................................................15

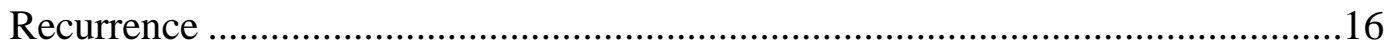

Chronicity of Barren State Prior to Surgery ………............................................16

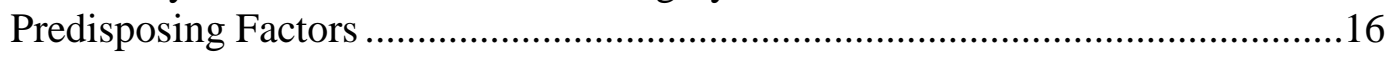

Intrauterine Infections ..............................................................................

Post-operative Fertility ...............................................................................17

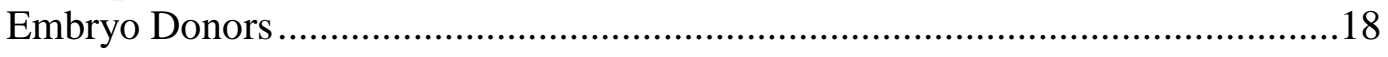


Chapter. Page

V. CONCLUSIONS...

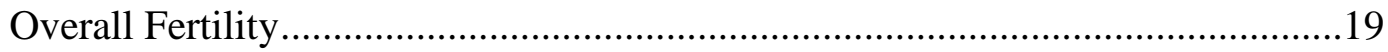

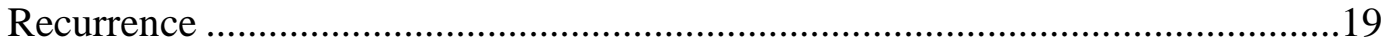

Chronicity of Barren State Prior to Surgery ......................................................20

Lesion Type and Severity .......................................................................21

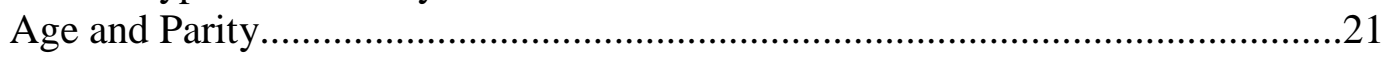

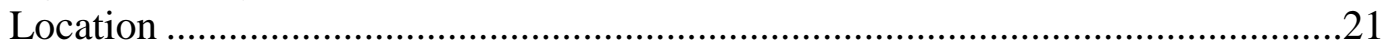

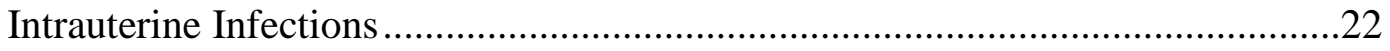

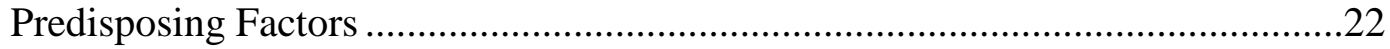

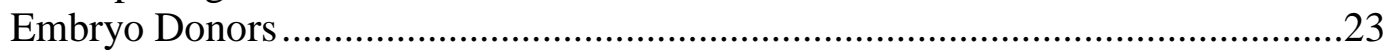

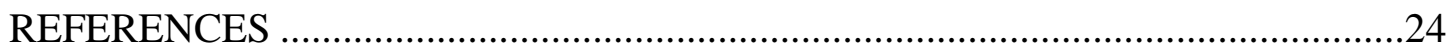




\section{LIST OF TABLES}

Table

Page

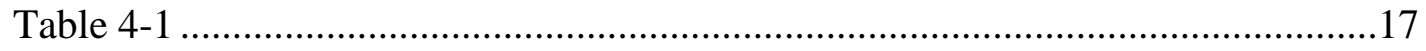




\section{LIST OF FIGURES}

Figure $\quad$ Page

Figure 3-1 Cervical Laceration ..............................................................

Figure 3-2 External Cervical Adhesion ..........................................................10

Figure 3-3 Internal Cervical Adhesion ...................................................... 10

Figure 3-4 Cervical Webbing................................................................... 10

Figure 4-1 Age of Mares with Lesion ........................................................... 14

Figure 4-2 Surgical Procedure …................................................................. 14

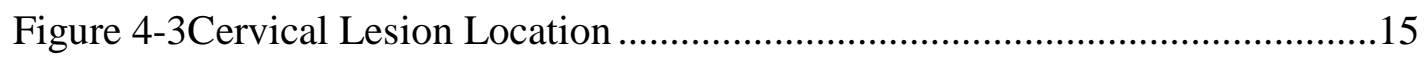




\section{CHAPTER I}

\section{INTRODUCTION}

Lacerations and adhesions of the cervix of a mare can end her breeding career if not properly diagnosed and treated in a timely manner. These defects lead to decreased cervical integrity resulting in infertility, early abortions, placentitis and septic foals costing the industry thousands of dollars in veterinary care and loss of progeny (Foss 1994). There have been rare instances where a congenitally incompetent cervix has been diagnosed (Blanchard 1982). These defects do not allow the cervix to close properly, and a tightly closed cervix is necessary for maintenance of pregnancy (Brown 1984). The treatment of choice for acquired defects is surgical correction (McKinnon 1993).

Often lacerations and adhesions are associated with dystocia (Blanchard 1982; Hurtgen 2006), contracted foals and abortions. Although a higher incidence of cervical trauma is seen with dystocia, normal parturition may result in cervical defects (Aanes 1988; Brown 1984). There is one report of a cervical laceration occurring due to breeding trauma in an Arabian mare (Aanes 1988). Another study suggests that older, multitocous mares may be predisposed to cervical laceration (Miller 1996).

The objective of this study was to determine the effect of surgical repair on fertility and whether treatment success is dependent on the lesion type and its chronicity. Fertility in this study is considered the birth of a live foal because there are many sequel to an incompetent cervix that may lead to loss of an embryo or fetus during pregnancy.. In the 1950's, it was observed that a cervical laceration of up to two-thirds of the thickness of the cervical wall may heal without interfering with subsequent fertility 
(Hagyard 1956, Thornbury 1975). In this study the severity and location of the lesion(s) will be evaluated to determine if they play a role in the post-operative fertility. It is recognized that the Thoroughbred industry does not recognized assisted reproductive techniques and as the majority of the mares in this study are comprised of Thoroughbred mares the use of embryo transfer post-operatively and subsequent fertility could only be assessed in small numbers, but is valuable data. In addition, the age of the mares, parity, duration of barrenness prior to surgery, infections and recurrence will also be evaluated. 


\section{CHAPTER II}

\section{REVIEW OF LITERATURE}

\section{Cervical Defects and Associated Fertility}

In the past, other studies used post-surgical pregnancy rates rather than birth of a live foal as the determinant for fertility. In 1984, Brown, et al. at Texas A\&M University reported pregnancy rates of $62 \%$ (Brown 1984) and Miller et al. from Rood and Riddle Equine Hospital reported pregnancy rates as high as 75\% (Miller 1996) after surgical repair of cervical lacerations. It was not reported how many of these mares went on to deliver live foals, which is the true purpose of a broodmare in today's equine industry. If a mare is not producing then she is costing the owner(s) money.

Foss et al. looked at the post breeding repair of cervical lacerations and the associated pregnancy rates. Five mares were presented with a cervical laceration that involved greater than $50 \%$ of the length of the cervix and the complaint of reproductive failure and absence of other detectable abnormalities. All the mares were bred artificially and then underwent surgical repair of the cervical defect two to three days later. Of the five mares all became pregnant, but only two gave birth to a live foal (Foss 1994).

\section{Recurrence of Lesion}

Surgical correction of the incompetent cervix improves the integrity of the cervix, but does not return the function to normal. In the cervical laceration, the corrected lesion heals via fibrosis. This scar tissue does not have the ability to relax, soften like normal cervical smooth muscle and scar strength usually does not exceed $70 \%$ to $80 \%$ of the normal tissue strength. This may account for an increased incidence of cervical 
laceration recurrence in subsequent parturitions. In the study done by Miller et al., recurrence of laceration lesions occurred in $26.4 \%$ of the mares after subsequent parturitions. In the study by Foss et al., one of the two mares that carried a foal to term had recurrence of its cervical laceration (Foss 1994).

No other recurrence rates were discussed in other studies, but it is generally accepted that mares with a previously corrected cervical defect will be more likely to tear than those who do not have a defect at all.

\section{Parity}

Multitocus mares are more likely to suffer from a cervical laceration than nulliparous mares (Ricketts 1989). Miller et al. reported that older, multitocus mares may be predisposed to this condition. The average age of the mares in the 1996 study was 12.8 years (Miller 1996).

There may be two primary reasons for this, the first being that mares that have gone through the act of parturition before generally have a briefer stage one labor and may not allow for adequate softening of the cervix as compared to a nulliparous mare. The second reason being that as a mare ages and goes through parturition multiple times, there are increasing amounts of fibrotic material laid down in the cervix that prevent the cervix from adequately softening and dilating. This scar tissue may be macroscopic, but generally considered microscopic and not visible with the traditional diagnostic tools used in veterinary medicine.

In contrast, in human medicine, nulliparous women seem to be at increased risk of having a cervical laceration than multiple parity women (Melamed 2009; Parikh 2007). This phenomenon may be due to a multitude of contributing factors and the human 
literature is somewhat vague. Some authors have eluded to early admittance of nulliparous women to the hospital in early stage one labor. This often leads to increased number of obstetrical interventions that may not allow for appropriate cervical ripening (Shields 2007).

Another contributing factor may be the arrest of descent during second stage labor. Women with arrest of descent during second stage labor have higher rates of cervical and perineal lacerations. In the study by Feinstein et al. in 2002, over $70 \%$ of all arrest of descent parturitions during second stage labor occurred in first deliveries (Feinstein 2002).

In addition, there appears to be a disparity between nulliparous and multitocous women in regards to "lightening," or settling of the presenting part into the pelvis. The timing of "lightening" is different from nulliparous to multitocous women and may suggest differences in uterine tone with multipara women have a more relaxed uterus while the myometrial tone not significantly different between the two groups. The simple relaxation of the lower pole of the uterus is a passive phenomenon and the disparity is untenable (Danforth 1982).

\section{Chronicity of Barren State Prior to Surgery}

In the study by Brown et al., which assess the overall conception rate of mares undergoing surgical repair of cervical lacerations, the $62.5 \%$ obtained may not be completely accurate as the study originally had thirteen mares presented and undergoing surgery, with eight of these mares later being bred and then only five of those eight mares conceiving and accounting for that $62.5 \%$. Of the mares that did not conceive their endometrial biopsy grades were found to be Kenney grades II and III (Brown 1984). 
These decreased grades may be due to chronic inflammation or infection or possibly due to the extended duration these mares were barren. The chronicity of the defects were not reported, but may have played a role in the post-operative fertility.

In human medicine cervical lacerations are detected and closed immediately without any significant affect on subsequent fertility (Parikh 2007; Melamed 2009). This repair in the acute state does not allow for chronic cervical incompetence which may lead to inflammation and infection.

It must also be stated that unrecognized or improperly repaired cervical lacerations may result in cervical incompetence in the human medicine. Often times submucosal separation of the fibrous connective tissue of the cervix or lacerations involving the internal os and uterus are often overlooked, resulting in repeated or habitual abortions during the second trimester in subsequent pregnancies (Hill 1982).

\section{Location}

No studies in veterinary medicine have assessed the location of cervical defects, but a study by Melamed, et al. in human medicine reported that many of the cervical lacerations in women occur on the lateral aspects of the cervix. Melamed also went on to state that location of the laceration was unrelated to mode of extraction, parity, cerclage, induction or position of fetal head (Melamed 2009). In 1982, Newton stated that most cervical lacerations in the woman occur invariably on the lateral aspects of the cervix except when induced by manual or instrumental trauma (Newton 1982). Both authors agree that the lateral aspects of the cervix are the most common areas for cervical lacerations, but have differing opinions as to the effect use of instrumentation have on location of the cervical trauma. 
VI. Predisposing factors

It is often believed that cervical lacerations in the mare occur most commonly secondary to dystocia or aggressive fetal extraction (Hurtgen 2006), but anecdotal information suggests that cervical lacerations are just as likely to occur during normal parturition as they would during dystocia (Evans 1979; Brown 1984). The incidence of dystocia in the mare ranges from $4 \%$ in Thoroughbred and Trotter type horses to $10 \%$ in Draft breeds (McKinnon 1993). No other study assessed if there is an increased incidence of dystocia in mares presented for cervical defects.

In human medicine, the primary predisposing factors appear to be induction of labor, nulliparous women, the use of vacuum or forceps during surgical vaginal delivery, cerclage, and episiotomy (Parikh 2007; Melamed 2009). 


\section{CHAPTER III}

\section{METHODOLOGY}

\section{A. Diagnosis}

Digital examination of the cervix is considered the gold standard method of diagnosis. Due to increased cervical tone, diestrus is the optimal time in the estrous cycle to evaluate for cervical lacerations. To perform a digital cervical exam appropriate restraint and sterility are required. The mare was placed in stocks or door of a stall with head restraint in the form of halter, lead rope or chain, nasolabial restraint and sedation were used if deemed necessary by the clinician. The tail was wrapped and the perineal area aseptically prepared. Using a sterile sleeve, a hand was passed through the vulva into the vaginal vault. A finger was inserted through the external os of the cervix to palpate the internal cervical mucosa and the thumb of the same hand was used to palpate the outer cervical mucosa in the vagina.

Thinning and absence of the muscle layers were consistent with previously healed cervical lacerations. These areas are generally palpated at the external os of the cervix and may feel like a wedge of the cervix is missing. This wedge may extend cranially for the entire length of the cervix or there are some instances where the muscle layers of the caudal and cranial openings of the cervix are intact but there is an absence of muscle in the interim. Adhesions can be detected in a similar manner and may involve tags of 
tissue extending from the external os of the cervix to the vaginal floor or wall, or they may incorporate the cervical canal itself.

Vaginal speculum exams and possible vaginoscopy or hysteroscopy may be used to diagnose cervical defects, but are not as sensitive as digital examination.

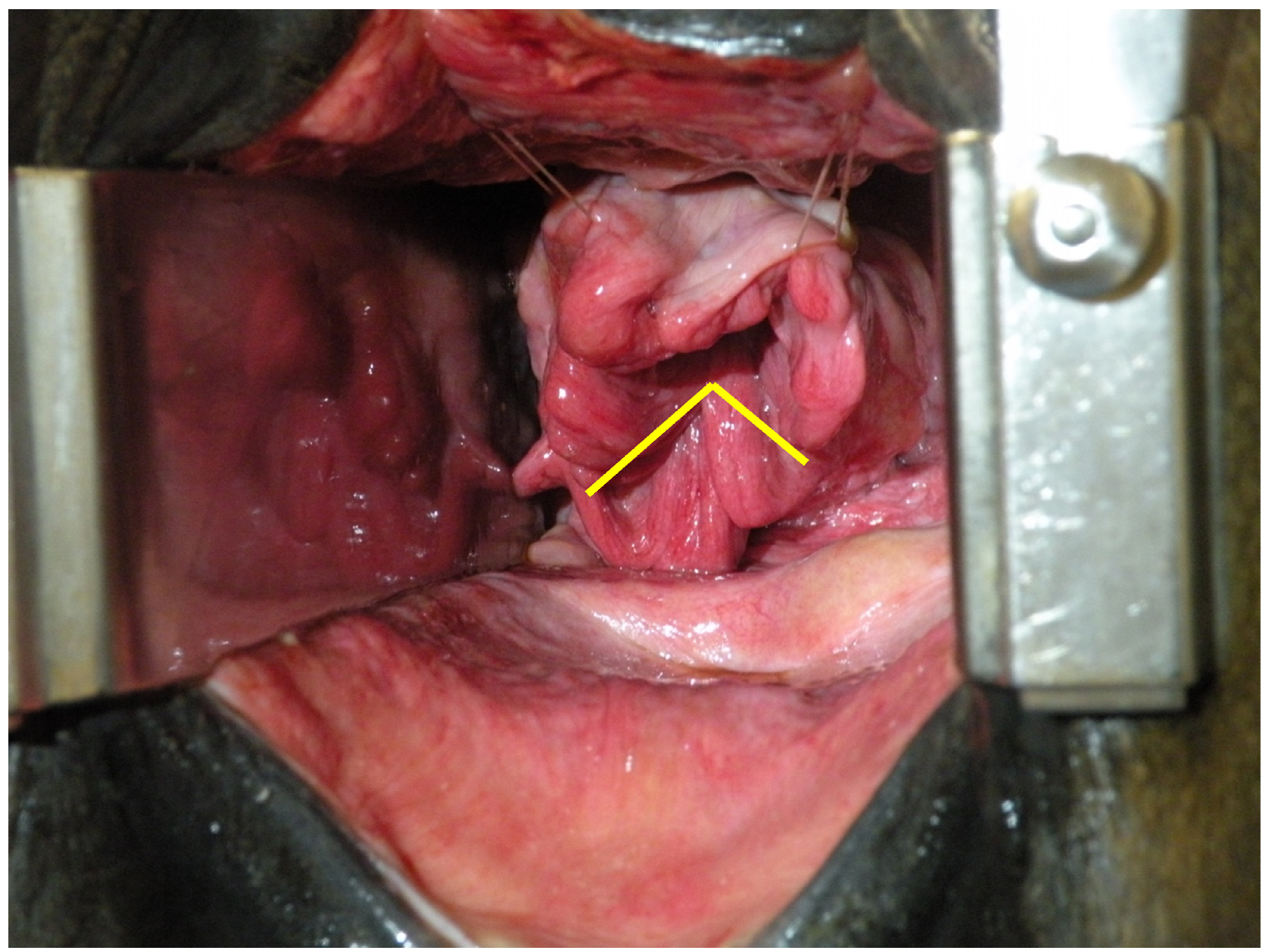

Figure 3-1(above): Cervical Laceration depicted by yellow lines spanning from the 4 to 7 o'clock location in the external os of the cervix. 


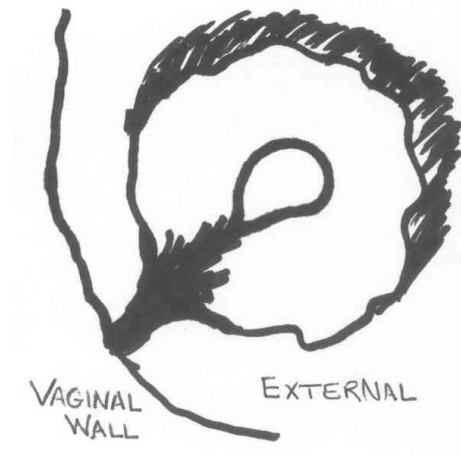

2

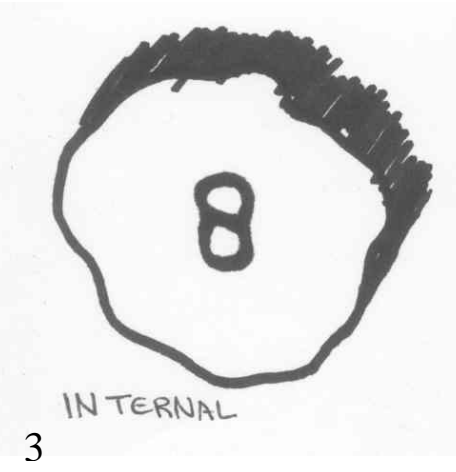

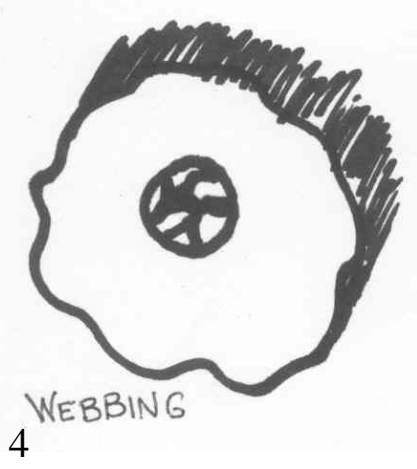

Figure3-2 (above): External cervical adhesion adhering the external os of the cervix to the vaginal wall at the 7 o'clock location not allowing the cervix to close completely.

Figure 3-3 (above): Internal cervical adhesion adhering the internal mucosa of the cervix together so that the cervix cannot appropriately open.

Figure 3-4 (above): Cervical webbing within the cervix is similar to internal cervical adhesions, but with very little space to for fluid or instruments to pass through the cervix.

\section{B. Surgical Technique-Cervical laceration}

The mares were restrained in standing position within stocks and sedated with a combination of detomidine and xylazine IM and IV. An epidural of xylazine (85 mg) and $2 \%$ lidocaine $(20 \mathrm{mg})$ diluted to a total volume of $6 \mathrm{~mL}$ with $0.9 \% \mathrm{NaCl}$ was administered into the epidural space using a 20 gauge 3.5 inch spinal needle. The rectum was evacuated of fecal material and the tail was wrapped and secured to an overhead crossbar of the stocks. The perineal area was aseptically prepared for surgery.

If closed vulvoplasty (Caslick 1937) was in place, the line of adherence was blocked with $2 \%$ lidocaine and the labial mucosal scar was opened with sharp scissors. While there is no normal innervations to the external os of the cervix, occasionally there may be some sensation, therefore a lidocaine saturated $4 \mathrm{x} 4$ gauze pad was placed over the external os of the cervix while the surgery table was prepped. A modified Finochietto-type retractor with $28 \mathrm{~cm}$ detachable blades was positioned in the vaginal 
vault and anchored to the base of the tied tail. Number 2 polyglactin 910 was used to place 2-3 stay sutures on either side and across from the defect in the cervix to retract the cervix caudally. Long handled instruments were necessary to perform the procedure in the vagina. The edges of the defect were freshened by incising or cutting along the edges of the defect from the external os of the cervix to beyond the cranial aspect of the lesion with a \#10 scalpel blade or sharp, long-handle Metzenbaum scissors. A three layer closure technique was performed with Number 0 polyglactin 910 in a continuous horizontal mattress pattern in the cervical lumen mucosa and a simple continuous pattern in both the cervical muscle and the vaginal mucosal layers.

\section{Surgical Technique-Cervical Adhesions}

The mare and perineal area were prepared as stated above. The cervical adhesion(s) were located by palpation per vagina and reduced by sharp or blunt dissection. Excess scar tissue may be trimmed as needed. Complications are rarely encountered in this procedure.

D. Peri- and Postoperative Support

Prior to surgery mares were given a single dose of procaine penicillin G $(22,000$ IU/kg IM), gentamicin sulfate (6 mg/kg IV), flunixin meglumine ( $1 \mathrm{mg} / \mathrm{kg} \mathrm{IV})$, and tetanus toxoid (1 mL IM). After surgery, mares were given flunixin meglumine $(1 \mathrm{mg} / \mathrm{kg}$ IV or PO) once a day for 3 days. Mares were returned to normal exercise and diet. Mares with cervical laceration repair were to have nothing per vagina for 3 weeks postop, while mares that were treated for cervical adhesions were treated topically with nystatin/thiostrepton/neomycin sulfate /triamcinolone acetonide ointment once daily or Seprafilm ${ }^{\circledR}$ Adhesion Barrier (Genzyme Corporation) on days 4 and 8 post-surgery. 
In a few cases, if the mare was deemed to have very severe adhesions that could not be completely treated with surgical intervention, the mare was placed on injections of Streptolysin O, a modified form of the hemolytic and cytotoxic bacterial toxin that that has been developed for the treatment of collagen disorders such as scleroderma, fibrosis, and scar and surgical adhesion formation in human medicine. The mechanism by which Streptolysin $\mathrm{O}$ can reduce or modulate collagen levels requires further investigation. It is believed that Streptolysin O affects cytokine expression, epithelial cell migration/proliferation, and modulates epithelial cell behavior including increased mobility, altered adhesion, and/or altered proliferation of keratinocytes and fibroblasts (Mamber 2004).

Mares were on reproductive rest for 4-6 weeks.

\section{E. Statistical Analysis}

In this study, fertility was defined as a mare that produced a live foal following defect diagnosis and repair. Parameters studied were age of the mare, parity (prior and postoperative), location of the defect, severity of the laceration, infertility prior to surgical intervention, incidence of dystocia, abortion or dead foals prior to surgical intervention when this information was available, prior uterine infections when this data was available, post-operative fertility and recurrence.

The statistical method used depended upon the nature of the variables in question. To test the statistical significance of the results the chi square test on a contingency table was used when qualitative data were compared. For continuous variable the t-test was used and if the factors were ordinal then the gamma statistic on a contingency table was implemented. $\mathrm{P}<0.05$ was considered statistically significant. 


\section{CHAPTER IV}

\section{FINDINGS}

\section{Age}

The average age of the mares in this study was 13 years of age with a range of 4 to 24 years (Figure 4-1).

II. Population \& Procedures

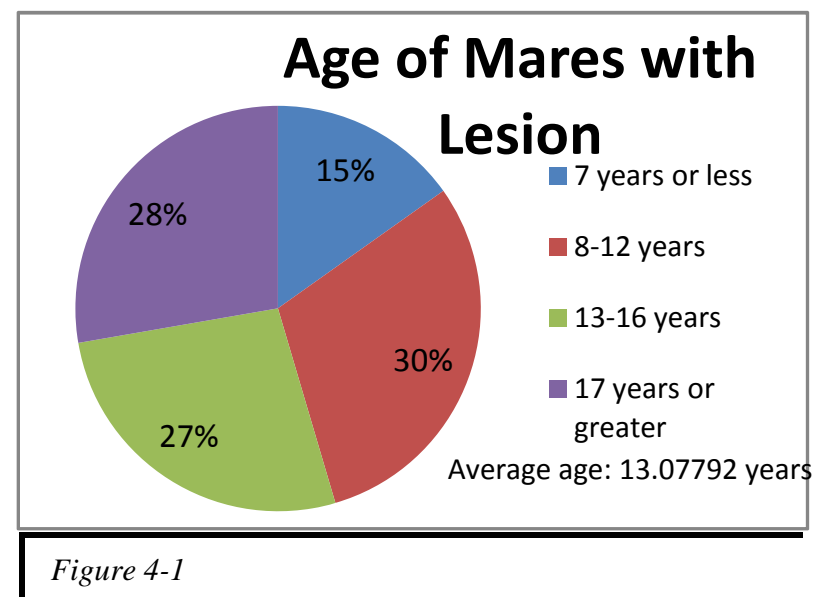

Between the years 2000-

2006, 242 procedures were performed on 187 mares. A total of 218 mares were diagnosed with a cervical defect. Of these 145 had surgery performed to repair a cervical laceration, 42 a cervical adhesion repair, 24 presented with a combination of a cervical laceration and adhesion that were corrected and 31 mares were diagnosed with a form of a cervical defect, but surgery was not performed.

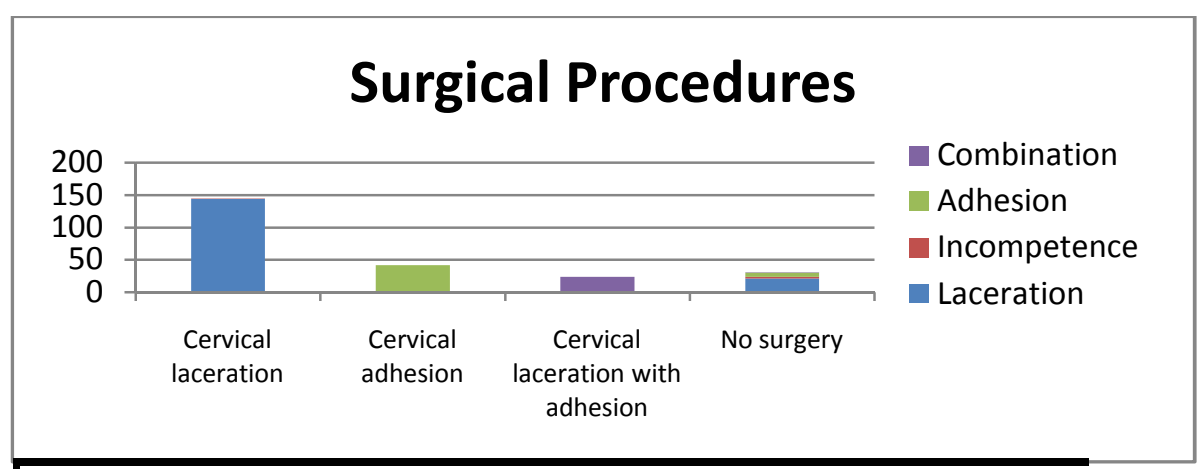

Figure 4-2 


\section{Parity}

Prior parity was considered in this study population to determine if multiple parity mares were predisposed to cervical defects. Approximately 5\% (10 of 218) of the mares diagnosed with a cervical defect were nulliparous prior to presentation. One mare appeared to have a congenitally incompetent cervix and another mare presented with a cervical laceration due to an intrauterine device (uterine marble) injury without history of conception or parturition, leaving approximately $94 \%$ of the mares as multiple parity mares.

IV. Lesion Location

Lesion location was

described as ventral, dorsal and lateral aspects of the cervix. Approximately $66 \%$ of the lesions diagnosed in this study were found in the ventral

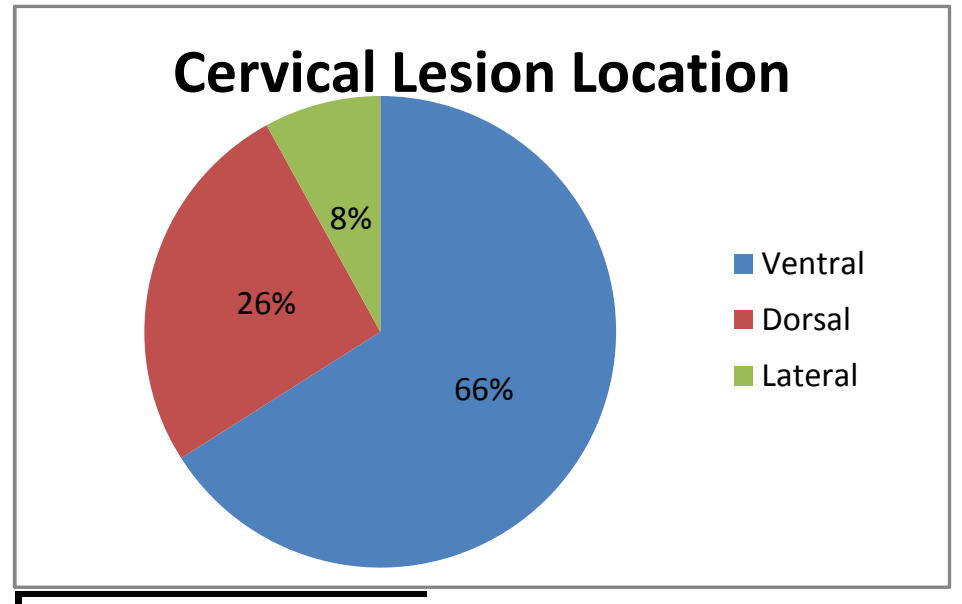

Figure 4-3 aspect of the cervix, $26 \%$ in the dorsal aspect, and $8 \%$ in the lateral aspects of the cervix. When assessing the post-operative fertility, lesion location was found to not be significant $(\mathrm{p}=0.0555)$ using chi square technique, but of the mares in this study with a dorsal lesion, $70 \%$ became fertile post surgical correction while those with a ventral lesion had only a $55 \%$ fertility rate after surgery. Also it was found that the lesion location did effect the number of foals a mare will have after surgery with mares having a dorsal lesion having 1.51 foals post surgery, while those with a ventral lesion had 1.07 foals $(p=0.0462)$ using the $t$ test technique. 


\section{Recurrence}

The incidence of recurrence of a cervical laceration in this group of mares with an additional surgical correction during the seven year period was $20.3 \%$. This leaves approximately 1 in every 5 mares that had a cervical laceration diagnosed and repaired with the possibility of having an additional cervical laceration during a subsequent foaling.

\section{Chronicity of Barren State Prior to Surgery}

When assessing post-operative fertility in mares we found that fertility is affected by the duration of prior barrenness. The greater the time the mare was barren prior to surgical correction the less likely the mare will be to conceive and carry a live foal to term $(\mathrm{p}=0.0005)$. In addition to this we found that mares that were barren for a greater period of time before diagnosis and surgical intervention had fewer number of foals after surgical correction $(\mathrm{p}=0.0024)$. We did find that the duration of prior barrenness to surgery did not significantly affect the time to conceive and carry a live foal to term after surgical correction $(\mathrm{p}=0.58868)$.

\section{Predisposing Factors}

History of dystocia, abortion and birth of dead foals was considered in this group of mares. In many of the patients, this history was not indicated in the file so only a small number of the mares in this study were assessed (104 of 218 mares). Of the mares assessed in this category, 13 had a history of dystocia, 58 had a history of abortion and 33 had a history of a dead foal (full term) which may be due to an unreported dystocia or another cause. History of a dystocia, abortion or dead foal did not have an apparent significant relationship with post-operative fertility $(\mathrm{p}=0.3476)$. Neither did it have a 
significant relationship with the lesion location $(\mathrm{p}=0.1274)$ nor lesion severity $(\mathrm{p}=0.2347)$

\section{Intrauterine Infection}

The incidence of infection at the time of diagnosis was determined and available in 47 of the 218 mares. Of the 47 mares with this data available, only 7 mares had a negative culture while the other 40 mares had an infection with bacteria, yeast or fungus. We found that infection status at the time of diagnosis had no detectable affect postoperative fertility $(\mathrm{p}=0.4297)$. Interestingly, the location of the lesion did not affect the infection status in this study ( $\mathrm{p}$ value 0.6548 ).

\section{Post-operative Fertility}

As far as overall fertility between mares that were diagnosed and had surgical repair the fertility rate with all types of lesions was $61.9 \%$ where as those mares that were diagnosed but did not undergo surgery had a post diagnosed fertility was $48.39 \%$ $(\mathrm{p}=0.1513)$. It was found that the lesion type, whether it is a cervical laceration, cervical adhesion or a combination of the two, did not have a significant relationship with fertility $(\mathrm{p}=0.9426)$

A breakdown of the lesion type, the duration of prior barrenness and the postoperative fertility are shown on the following table:

\begin{tabular}{|c|c|c|c|c|c|c|}
\hline & & & \multicolumn{2}{|c|}{$\begin{array}{c}\text { Post-operative fertility with duration of } \\
\text { prior barren state }\end{array}$} & Total post- \\
\cline { 4 - 6 } Lesion Type & $\begin{array}{c}\text { Number } \\
\text { Diagnosed }\end{array}$ & $\begin{array}{c}\text { Number } \\
\text { surgical } \\
\text { cases }\end{array}$ & $\begin{array}{c}\text { Less than 12 } \\
\text { months }\end{array}$ & $\begin{array}{c}\mathbf{1 3 - 2 4} \\
\text { months }\end{array}$ & $\begin{array}{c}\text { Greater } \\
\text { than or } \\
\text { equal to 25 } \\
\text { months }\end{array}$ & $\begin{array}{c}\text { Torative } \\
\text { fertility }\end{array}$ \\
\hline Lacerations & 166 & 145 & $63.6 \%$ & $59.1 \%$ & $28.6 \%$ & $53.7 \%$ \\
\hline Adhesions & 48 & 42 & $70.0 \%$ & $62.5 \%$ & $50.0 \%$ & $59.5 \%$ \\
\hline $\begin{array}{c}\text { Lacerations } \\
\text { and } \\
\text { Adhesions }\end{array}$ & 25 & 24 & $75.0 \%$ & $62.5 \%$ & $37.5 \%$ & 58.3 \\
\hline No surgery & 31 & & & & & \\
\hline
\end{tabular}

Table 4-1 
After assessing this breakdown, it was noted that the post-operative fertility in mares with greater than 24 months chronicity of barrenness prior to diagnosis and surgery decreased dramatically and was very similar to the fertility rate seen in mares that did not undergo surgery. Given this information, further breakdown of the mares was performed and we discovered that mares that were diagnosed with a cervical defect (laceration, adhesion or a combination of the two) and they were surgically repaired within a 24 month window of the barren state had a post-operative fertility rate of $67.24 \%$, while mares that did not have surgery or had been barren for greater than 24 months before diagnosis and surgery had a post-operative fertility rate of $41.78 \%(\mathrm{p}=0.0003)$.

\section{Embryo Donors}

Some of the non-Thoroughbred mares in this study did not carry a foal to term, but did go on to become successful embryo donors. Of the 24 non-Thoroughbred mares, 6 mares $(25 \%)$ conceived and gave birth to a live foal, 9 others $(37.5 \%)$ were successful embryo donors with the last 9 mares (37.5\%) remaining infertile after diagnosis and surgery (one mare in this last group did not undergo surgery and was retired after diagnosis). 


\section{CHAPTER V}

\section{CONCLUSIONS}

\section{Overall Fertility}

The overall fertility rate of $61.9 \%$ was determined by the conception and birth of a live foal. This is similar to the pregnancy rate of $62 \%$ found by Brown et al. in 1984, but still much lower than the $75 \%$ pregnancy rate found by Miller el al in 1996 . These other studies used post-surgical pregnancy rates rather than birth of a live foal as the determinant for fertility. This may account for the lower percentages seen in our study. This discrepancy may also be due to the larger population in this study, the increased incidence of diagnosis and severity of the lesions for which surgical correction was attempted. Although the post-surgical fertility rate is lower overall (63.1\%), when compared to the fertility of affected mares that did not receive surgery $(48.39 \%)$ the fertility was greatly improved.

\section{Recurrence}

Surgical correction of the incompetent cervix improves the integrity of the cervix, but does not return function to normal. In the cervical laceration, the corrected lesion heals via fibrosis, as any scar does. This scar tissue does not have the ability to relax, soften as normal cervical smooth muscle, and this could account for an increase 
incidence of recurrence in subsequent parturitions. In our study, 38 of the 187 mares receiving surgery to repair a cervical tear had 2 or more surgical corrections. This gave us an overall diagnosed and treated recurrence rate of approximately $20.3 \%$, which is slightly lower than the previous study done by Miller et al. where $26.4 \%$ of the mares presented multiple times for surgical repair after subsequent parturitions (Miller 1996). Again this may be due to the larger population and the severity of the lesions seen during this time period.

\section{Chronicity of Barren Period Prior to Surgery}

The earlier the lesion is diagnosed and repaired the better the prognosis a mare can be given to return to fertility. While post-operative fertility rates remained similar between the less than 12 months and 13-24 month duration of pre-operative bareness, there was a dramatic decrease in this percentage in mares that had been barren for 25 months or greater.

Mares that have a cervical laceration diagnosed and repaired within the first year lose little fertility, if managed appropriately. They will also have a greater number of foals compared to mares diagnosed and repaired with times of greater than or equal to 25 months duration of being barren prior to surgical correction. This post-operative fertility in the former group is cut in half and is less than $30 \%$.

Cervical adhesions have a better prognosis than cervical lacerations, but follow the same downward trend as the duration of prior bareness increases.

The prompt diagnosis and repair of a cervical defect yields a more favorable prognosis. This may account for the lack of effect in fertility in human cervical lacerations. If the laceration does not involve the uterus, and is diagnosed and repaired at 
the time of parturition there is relatively no significant effect on subsequent pregnancies (Melamed 2009).

\section{Lesion Type and Severity}

The type of cervical lesion does play a role in post-operative fertility in the mare. Cervical lacerations alone carry a poorer prognosis than cervical adhesions and the combination of cervical lacerations and adhesions, especially if the mares that had been barren equal to or exceeding 25 months.

The severity of the lesion as described in this study is the length of the cervical laceration or the extent of cervical involvement. There does not appear to be a relationship with the severity of a laceration and the post-operative fertility as was suspected. As long as the cervical defect can be closed completely by surgical repair, severity plays little role.

\section{Age and Parity}

The mean of 13 years of age for the mares in this study correlates with that derived in the 1996 study by Miller, et al. (Miller 1996). Approximately $94 \%$ of the mares presenting for cervical defects had multitocuos. We did encounter one mare that presented with an incompetent cervix that was suspected to have been congenital and one other that had a cervical defect due to complications with an intrauterine contraceptive device designed to suppress estrus, otherwise known as an intrauterine marble.

\section{Location}

The most common location of the lesions in this study was in the ventral aspect of the cervix. This is probably due to the passage of hooves through the cervix and the presentation of the foal and the position of the mare during parturition which is generally 
some variation of sternal. This is dramatically different than the cervical defects diagnosed in humans, where the lesions occur primarily in the lateral aspects (Melamed 2009).

\section{Intrauterine Infections}

It had been suspected that many of these mares were infected at the time of diagnosis as the integrity of the cervix had been compromised allowing for bacteria to enter the uterus and introduce pathogens to an otherwise sterile environment. Laboratory data was only available for 47 of the mares in this study. Of the 47 mares only 7 (14.9\%) had negative cultures at the time of diagnosis. Of the remaining 40 mares, $14(29.8 \%)$ had gram positive bacterial infections, $12(25.6 \%)$ had gram negative bacterial infections, $6(12.7 \%)$ had mycotic infections, and $8(17.0 \%)$ had multiple organisms comprising their uterine infections.

Due to lack of statistical power, a correlation between intrauterine infections and post-operative fertility could not be made. It should be noted that of the mares that did not have intrauterine infections at the time of diagnosis, none of them possessed dorsal defects. It had been hypothesized that location of the cervical defect may contribute to intrauterine infections, but this does not appear to be significant according to these data.

VIII. Predisposing Factors

In this study data were collected on 104 mares of the 218 diagnosed with cervical defect. These mares had been diagnosed with a dystocia (13 of 104), abortion (58 of 104) or birth of a dead foal (33 of 104). Of the remaining 114 mares there is no known history if any of these events occurred or if there was a normal foaling. Because we do not have the statistics of normal parturition we cannot determine if there is a correlation between 
these events and cervical defects. It is interesting to note that 104 mares of the 218 mares in the study had a history of such an event, which equates to $47.7 \%$.

The other predisposing factors include age of the mares, with an average being 13.07 years of age and multiple parity mares. As discussed previously, the older mares that have undergone parturition multiple times may have increased fibrotic tissue within the cervix, preventing it from adequately softening and dilating, or the duration of stage one labor is shorter in these multiple parity mares which may not allow for adequate softening of the cervix.

\section{Embryo Donors}

Although surgical repair of the cervix may result in greater pregnancy rates many of these pregnancies may result in an early or late term pregnancy loss, placentitis, prolonged parturition, or foals suffering from septicemia or neonatal maladjustment syndrome. This was the purpose for defining fertility in this study as the birth of a live foal. Several of the non-Thoroughbred mares in this study have gone on to be successful embryo donors post-surgery, but were not included in the fertility rate as they did not carry the foal to term themselves, but it should be noted that they were able to conceive. Of the 24 non Thoroughbred mares 9 mares went on to be successful embryo donors $(37.5 \%)$. If the embryo donor data were added to the fertility data then a slight increase in post-operative fertility was noted, with the greater than 2 years cervical laceration numbers in particular, moved from $28.6 \%$ to $37.1 \%$. 


\title{
REFERENCES
}

\author{
Reference List
}

Aanes WA. Surgical management of foaling injuries. Vet Clin North Am Equine Pract 4: 417-438, 1988.

Blanchard TL, Evans LH, Kenney RM, Hurtgen JP and Garcia MC. Congenitally incompetent cervix in a mare. J Am Vet Med Assoc 181: 266, 1982.

Brown JS, Varner DD, Hinrichs K and Kenney RM. Surgical repair of the lacerated cervix in the mare. Theriogenology 22: 351-359, 1984.

Caslick EA. The vulva and the vulvo-vaginal orifice and its relation to genital health of the Thoroughbred mare. Cornell Vet. 27: 178-187, 1937.

Newton M. Other complications of labor. In: Danforth DN, editor, Obstetrics and Gynecology. Harper \& Row. Philadelphia. pp 735-736, 1982.

Feinstein U, Sheiner E, Levy A, Hallak M, Mazor M. Risk factors for arrest of descent during the second stage of labor. International Journal of Gynecology \& Obstetrics 77: 7-14, 2002.

Foss RR, Wirth NR and Kutz RR. Post-breeding Repair of Cervical Laceration. AAEP Procedings 1994 11-12, 1994.

Hagyard CE. Reproductive diseases of mares. Cornell Vet. 46: 329-337, 1956. 
Hill EC. Disorders of the Uterine Cervix. In: Benson RC, editor, Current Obstetric \& Gynecologic Diagnosis \& Treatment. Lange Medical Publications. Los Altos. pp 228, 1984.

Hurtgen JP. Pathogenesis and treatment of endometritis in the mare: A review. Theriogenology 66: 560-566, 2006.

\section{Mamber SW, Long V, Rhodes RG, Pond-Tor S, Wheeler LR, Fredricks K, Vanscoy} B, Sauniere JF, Steinschneider R, Laurent JC, McMicheal J. The use of streptolysin $\mathrm{O}$ for the treatment of scars, adhesions and fibrosis: initial investigations using murine models of scleroderma. Nonlinearity Biol. Toxicol. Med. April 2(2): 67-87, 2004.

Melamed N, Ben-Haroush A, Chen R, Kaplan G, Yogev Y. Intrapartum cervical lacerations: characteristics, risk factors and effects on subsequent pregnancies. Am J Obstet Gynecol. April: 388-389, 2009.

Miller C, Embertson RM and Smith S. Surgical Repair of Cervical Lacerations in Thoroughbred Mares: 53 cases (1986-1995). AAEP Proceedings 42: 154-155, 1996.

Mitchell RN, Cotran RS. In: Kumar V, Cotran RS, Robbins SL, editors, Robbins Basic Pathology. Saunders. Philidelphia. pp 76, 2003.

Parikh R, Brotzman S, Anasti JN. Cervical lacerations: some surprising facts. Am J Obstet Gynecol. May: e17-e18, 2007.

Ricketts S. The barren mare: Diagnosis, prognosis, prophylaxis and treatment for genital abnormality. In Practice July: 156-164, 1989. 
Sheilds SG, Ratcliffe SD, Fontaine P, Leeman L. Dystocia in Nulliparous Women. American Family Physician 75;11: 1671-1678,2007.

Thornbury RS. Diseases of the Vulva, Vagina and Cervix of the Thoroughbred Mare. New Zealand Veterinary Journal 23: 277-280, 1975.

Vandeplassche M. Dystocia. In: McKinnon AO, Voss JL, editors, Equine Reproduction. Williams \& Wilkins. Philidelphia. pp.578, 1993. 
VITA

Chelsea Lynn Makloski-Cohorn BS, DVM

Candidate for the Degree of

Master of Science

Thesis: POST-OPERATIVE FERTILITY IN MARES WITH CERVICAL DEFECTS

Major Field: Veterinary Biomedical Sciences

Biographical:

Personal Data: Clinical Resident in Theriogenology at Oklahoma State University Center for Veterinary Health Sciences.

Education:

Completed the requirements for the Master of Science in Veterinary Biomedical Sciences at Oklahoma State University, Stillwater, Oklahoma in July, 2009.

Experience: Completed an internship at Rood and Riddle Equine Hospital in 2007 and completed a clinical residency in theriogenology at Oklahoma State University in June, 2009. Currently, I am Assistant Professor of Clinical Sciences for Theriogenology at Oklahoma State University Center for Veterinary Health Sciences.

Professional Memberships: AVMA, AAEP, SFT 
Name: Chelsea Lynn Makloski-Cohorn

Institution: Oklahoma State University
Date of Degree: July, 2009

Location: Stillwater, Oklahoma

Title of Study: POST-OPERATIVE FERTILITY IN MARES WITH CERVICAL DEFECTS

Pages in Study: 25 Candidate for the Degree of Master of Science

Major Field: Veterinary Biomedical Sciences

Scope and Method of Study: Retrospective study

Findings and Conclusions:

Cervical lacerations and adhesions occur secondary to trauma of the cervix in mares, and are most commonly associated with parturition, abortion, or breeding injuries. Such defects affect cervical integrity and may lead to infertility due to chronic uterine infections. Mares that become pregnant are also at risk for ascending placentitis, abortions and septic foals. Surgery is the treatment of choice for cervical defects and has minimal risks associated.

We selected variables in this study that were not assessed in past studies and include: type of lesion (laceration, adhesion, or both), location of lesion (dorsal, ventral or lateral), duration of infertility prior to surgery, and incidence of defect recurrence. This study examined if certain types of lesions were more successfully treated with surgery relative to others. It will also assess the affect or prior chronicity of barren state, uterine infections and the age of the mare have on prognosis.

Mares diagnosed with a cervical defect and had surgical repair within a 24 month barren state had a $67.24 \%$ post-operative fertility rate, while mares that did not undergo surgery or had been barren for greater than 24 months prior to surgery had a fertility rate of $41.78 \%(\mathrm{p}=0.0003)$. These findings indicate that expedient diagnosis and surgical treatment are necessary to optimize the mare's fertility.

ADVISER'S APPROVAL: Dr. G. Reed Holyoak 